\title{
Integration of the controlling mechanism into the Deming-Shewhart PDCA cycle in the context of digitalization
}

\author{
Munir Kalemulloev ${ }^{1}$, Alexey Platov, ${ }^{2, *}$, and Anna Silaeva ${ }^{3}$ \\ ${ }^{1}$ Tajik National University, 73402517 Dushanbe, Tajikistan \\ ${ }^{2}$ Moscow (Senkevich) State Institute of Physical Culture, Sports and Tourism, 125499 Moscow, \\ Russia \\ ${ }^{3}$ Russian State University of Tourism and Service, 141221 Cherkizovo, Russia
}

\begin{abstract}
Digitalization provides an increase in the efficiency of production management, and also opens up wide opportunities for the formation of models of management decisions using predictive technologies. Digital technologies systematize and combine information flows of different origins. Thus, a predictive model of strategic and tactical production management is created. A condition for the successful digital transformation of economic sectors is the development of a set of measures for the technical re-equipment of enterprises. This article proposes an integrated controlling model based on the concept of continuous improvement of PDCA processes. The PDCA cycle model is adapted to the process of technical re-equipment of the enterprise and is integrated with the controlling mechanism based on the process approach. Such integration will ensure an increase in the controllability of the technical re-equipment process, improve the coordination of personnel actions, and create effective feedback mechanisms. The proposed model will increase the validity and efficiency of management decisions.
\end{abstract}

\section{Introduction}

Automated analysis of big data involves more than just analyzing huge amounts of information. The problem is that enterprises can have access to a huge amount of their data without having the necessary tools to relate that data. The most important condition for the successful development of enterprises is the ability to record and analyze these arrays and flows of information. It should be especially noted the need to combine information flows that do not have a common origin, but combining them makes it possible to obtain a predictive model $[1,2]$.

The inclusion of new technological trends in the field of digital transformation in the development program of enterprises will help to provide them with competitive advantages, since digitalization improves efficiency and quality in production, and also provides ample opportunities for new models of management decisions based on predictive technologies.

\footnotetext{
* Corresponding author munir-k@list.ru
} 
The theoretical foundations of controlling began to be laid with the emergence and development of the provisions of process management. In the second half of the 20th century, the "control" function was divided into "reporting" and "budgeting", thereby laying the foundation for the development of controlling tools [3].

The development of controlling was accompanied by an increase in disputes between scientists and practitioners, adherents of various concepts about the essence, functionality and tools of controlling [4]. Despite the many scientific publications on this topic, disputes among the scientific community continue [5].

To date, a number of concepts have been formed that reflect the main trends in the development of the theory of controlling. Within the framework of the conceptual foundations of the functioning of the controlling process at enterprises, this issue, in our opinion, should be considered in two aspects:

- firstly, taking into account the peculiarities of the organizational structure of enterprises;

- secondly, examining controlling itself as a reflection of the external (strategic controlling) and internal environment (operational controlling) of the enterprise.

Thus, the starting point for developing the concept of the enterprise controlling process should be its functional structure.

Controlling is based on the decomposition method, where the goal is at the top level, followed by controlling functions, elements, etc. Depending on the structure of the enterprise, the controlling model can be built both for the enterprise as a whole and for individual structural divisions. One of the most important elements of controlling is management accounting, associated and integrated with accounting [6].

Today it is no longer enough to build an effective management system simply to collect information within the framework of management accounting, to plan indicators within the framework of budgeting and analysis of the results obtained. The economic situation in the market changes very quickly and often requires an immediate decision. This determines the level of management and the need to apply a comprehensive base of management approaches in the form of a controlling system. Controlling includes a complex of subsystems: management accounting, budgeting, analysis, activity control and monitoring. The complex application of these subsystems provides quick management decisions [7].

According to the opinions of modern researchers, the main task of controlling is the orientation of the management process to achieve the goals facing the enterprise, including strategic ones [8]. Therefore, it is important to trace the relationship between the strategic and operational levels of controlling [9].

Business process outcome planning provides the ability to monitor key performance indicators. Monitoring makes it possible to track indicators in real time and compare them with planned ones, draw conclusions about the dynamics of business processes, identify failures, recognize a crisis, reduce the degree of risk, and adjust strategies [10].

For the successful transformation of industries into a digital economy, it is necessary at the enterprise level to develop a set of measures for technical re-equipment in order to use digital technologies both in production and in the management process. To achieve positive results from the implementation of a technical re-equipment project, competently developed management processes and correct approaches to their implementation are required. Obviously, enterprises with mature process management capabilities manage them in a closed loop with feedback, including planning, design, implementation, execution, measurement, control and improvement (improvement).

\section{Methods}

To increase the efficiency of industrial enterprises, it is necessary to investigate the essence and features of the model of continuous improvement of processes - PDCA, adapted to the 
process of technical re-equipment, and to develop a controlling mechanism incorporated with the PDCA model.

The research is based on the dialectical method of cognition, a systematic approach, general scientific methods of economic and comparative analysis, operational and strategic management and information support of managerial decisions. In order to make a managerial decision, it is necessary to understand not only the conceptual apparatus, but also be able to skilfully apply in practice the methodology of managerial decisions, methods of developing managerial decisions, organizing the development of managerial decisions, assessing the quality of managerial decisions.

\section{Results and discussion}

For the implementation and use of any technology that improves the performance of an organization, it is reasonable to apply the PDCA (Plan-Do-Check-Act) method - the organizational management cycle, or the Deming-Shewhart cycle. According to this model, management should cyclically go through the following stages: planning (design), implementation (work), control (analysis), adjustment (adjustment) [11].

Technical re-equipment as a continuous process of innovative development of an enterprise seems to us to be a closed cycle. Therefore, for this process, it is advisable to apply the organizational management cycle, or the Deming-Shewhart cycle. However, in order to increase the efficiency of the process of technical re-equipment of the enterprise, it is necessary to adapt the model of continuous improvement of PDCA processes and incorporate a controlling mechanism into it. The strengthening of the PDCA model by the controlling mechanism is primarily due to the fact that controlling is a special concept for managing all enterprise processes, has a wide range of modern tools to improve the quality of management activities.

Below are the essence and features of the PDCA model, adapted to the process of technical re-equipment of an enterprise with an incorporated controlling mechanism, within the framework of the process approach.

Development of a technical re-equipment project (Plan).

The purpose of the stage is to make sure that the context of the technical re-equipment process and its internal structure correspond to the strategic development goals of an industrial organization. The description of the business context is to develop a technical reequipment project. It is a way to achieve a deep understanding of the relationship between the re-equipment process and its external environment. This critical step in understanding the goals of the retooling process is completed when at least the following information is received:

- consumer of the process of technical re-equipment;

- the exit of the process of technical re-equipment and a clear understanding of why it is of value to the consumer;

- how the process of technical re-equipment and its output correspond to the mission of the enterprise and work towards its strategic technical and technological goals;

- input (s) of the technical re-equipment process, the event (s) that trigger the execution of the process, and the channels through which this launch can occur;

- external or internal policies and regulations that impose restrictions on the design and implementation of the retooling process;

- initial values of performance and efficiency indicators (if we are talking about an existing business process);

- target indicators of efficiency and effectiveness of the future version of the technical reequipment process. 
After the business context is fixed in the approved project, you can start designing the internal structure of the technical re-equipment process. If it is well designed, then as a result we get at least the following clearly formulated points:

- actions that make up the process, activities that implement the technical re-equipment of an industrial organization;

- tangible results created during the implementation of process activities, and the states through which they pass;

- information systems involved in the execution of the process;

- places of performed actions and places of storage of material results related to the process;

- specific events limiting the execution of the process;

- metrics and measurement points for process performance indicators.

At enterprises that are unable to properly organize information and analytical support for the planning stage through the controlling mechanism, the development of the technical reequipment process is based on assumptions and intuition. Such organizations often suffer from multidirectional efforts, internal strife, operational conflicts, breaks in the value chain into functional enclaves. The advantage of the PDCA model with incorporated Controlling is that it supports the planning process. It consists in the implementation of an integrated approach in the development and development of planning methods, the formation of information necessary for planning, its sources and ways of obtaining. TP Controlling is designed to solve the following tasks:

- to provide information support in the development of measures for the technical reequipment of the TP included in the project;

- ensure the coordination of individual events in terms of time and content;

- to form and improve the structure of the TP planning system;

- establish information needs and time frames for the stages of the planning process;

- to coordinate the process of information exchange;

- to check the developed measures and the TP project as a whole for completeness and feasibility;

- coordinate and aggregate individual activities of the TA project in terms of time and content and integrate them into a single TA project.

The controlling mechanism determines how and when it is necessary to plan, assesses the possibility of implementing the planned activities and the TP project as a whole, and the planning technology is developed.

Implementation of the project of technical re-equipment (Do).

The purpose of this stage of the PDCA cycle is to implement the process according to the specification developed during the planning stage. In our case, this means implementing the project for the technical re-equipment of an industrial organization developed and approved at the previous stage. The implementation of a technical re-equipment project is not limited to any specific format, but, as a rule, includes the following actions:

- creation of new roles and powers or modification of existing ones;

- design or restructuring of functional units;

- development or completion of information systems, including functional applications and automation of processes and workflows;

- development and implementation of support tools such as standards for operating procedures, instructions and guidelines;

- opening of new channels and points of interaction of the process participants; - creation and implementation of monitoring process performance indicators, dashboards for monitoring performance, as well as escalation mechanisms.

The "Action" stage of the PDCA cycle also includes the execution of the process from the moment it is put into operation. In other words: 
- the process is started by initiating events;

- the process receives inputs;

- actions are performed;

- intermediate results are produced;

- the final results of the process are produced and transmitted to their intended purpose.

At this stage, several controlling functions are implemented at once: organization, coordination and primary accounting. In terms of the implementation of organizational support for the process of technical re-equipment by controlling, the following tasks are solved:

- formation of a rational organizational structure of interaction of all participants in the process of technical re-equipment in accordance with the goals, objectives and main activities of the project of technical re-equipment;

- formalization of proposals to rationalize the organizational interaction of the participants in the TP process in the form of appropriate provisions on the organizational structure and involved structural units;

- making proposals on the content of job descriptions.

Support for the implementation of the technical re-equipment project through the coordination function is carried out through:

- rational coordination of actions of participants in the process of technical re-equipment;

- coordination of operational management decisions with the tasks and purpose of technical re-equipment, strategic orientation of the decisions made;

- streamlining of information flows arising and consumed during the process of technical re-equipment of industrial organizations.

In the field of accounting, controlling tasks include the formation of a system for collecting and processing primary accounting information, which is essential for making management decisions during the project implementation process.

The choice and development of accounting methods, criteria for assessing the implementation of each of the stages of activities and the project as a whole are of great importance. The main tasks in the field of accounting can be designated:

- recording and primary processing of data referred to accounting information;

- development and maintenance of the functioning of the accounting system for the process of technical re-equipment of an industrial organization;

- unification of methods and criteria for assessing the effectiveness of the implementation of activities and the project as a whole.

Analysis of the implementation of the technical re-equipment project (Check).

The purpose of this stage of the PDCA cycle is to measure the performance of the process and compare it with the expected performance. Process performance is driven by consumer expectations.

This stage is supported by the controlling mechanism through the implementation of accounting, analysis and control functions.

At this stage, the list of accounting controlling tasks includes:

- fixation of information obtained as a result of solving problems of analysis and control;

- systematization of the most significant data for decision-making;

- ensuring the implementation of the accounting function.

In order to support the function of analyzing the implementation of a technical reequipment project, the controlling mechanism solves the following tasks:

- determination of methods, techniques and algorithms for analytical processing of accounting information; - implementation of analytical procedures for information processing in accordance with established methods, techniques and algorithms;

- formation of a system of calculated indicators for the implementation of further control procedures; 
- interpretation of the analysis results;

- provision of reporting documentation and analytical notes in accordance with the established reporting forms and the timing of their submission.

Control over the implementation of project activities involves the development of control methods, determination of points and timing of control, as well as the content of control operations. On the basis of the project documentation, a package of control documentation is developed, which sets the timing of control procedures and their content. To do this, at the planning stage, a system of control indicators is developed and planned values of control values are established, and an admissible corridor of deviation of control indicators is determined. In accordance with the control documentation, the actual and planned values of the control indicators are compared and the degree of achievement of the set goal is established. Then the deviations are analyzed and the reasons for their appearance are established in order to eliminate them.

The main tasks of controlling in the field of control are as follows:

- the establishment of parameters controlled in time and content sections;

- comparison of planned and actual values of control indicators for measuring and assessing the degree of achievement of the TP goal;

- determination of the corridor of permissible deviations of the values of the control indicators;

- identifying deviations of the actual values of control indicators from the planned ones, establishing the reasons for the identified deviations and developing proposals for eliminating the identified deviations and the causes that caused them.

At this stage, the main task of controlling is not control over the participants in the implementation of the project for the technical re-equipment of an industrial organization, but encouraging them to self-control and increasing motivation.

Correction of the project of technical re-equipment (Act).

The purpose of the adjustment stage of the PDCA cycle is to analyze and respond in accordance with the data collected during the analysis stage on the effectiveness of the process. This stage ensures the high-quality functioning of the process, despite changes in the environment.

There are two types of adjustments that can be made:

- actions with individual process instances (intervention in real or near real time);

- identifying and planning changes in the description and implementation of the process (i.e. measuring how the process instances are to be executed in a future release).

In general terms, the adjustment stage includes the following actions:

- collection and aggregation of data and observations collected at the analysis stage;

- analyzing this data and compiling a list of critical comments from the list (i.e. requirements for the design of a future version of the process);

- ranking of all requirements for the future version of the internal structure of the process, which should be implemented at the next stage.

\section{Conclusion}

Implementation of the controlling mechanism in the course of continuous improvement of the efficiency of technical re-equipment of the organization within the framework of the adapted PDCA model will allow:

- to strengthen the controllability of the technical re-equipment process by collecting, analyzing and forming a reliable and complete information base both for all processes and for external factors that affect the TP process and require accounting; 
- clearly coordinate the actions of personnel and third-party specialists involved in the implementation of the TP process, the most rational distribution of their duties and consolidate areas of functional responsibility;

- measure and evaluate the actual values of the parameters of the production system of the enterprise; organize more effective supervision and control over the progress of the TA process and effective feedback;

- reasonably and promptly make management decisions during the implementation of the TP project. Directions for further research are in the development of methods for applying various technologies of the digital economy at each stage of the PDCA cycle.

\section{References}

1. C. Ke, K. Wang, CSAE, 1 (2018)

2. J. Patel, IEEE, 2691 (2019)

3. M. Prakash, IRJMST, 4 (2), 1010 (2013)

4. S. Căpuşneanu, D. Topor, C. Maria, A. Marin-Pantelescu, I. Oncioiu, Improving Business Performance Through Innovation in the Digital Economy, 156 (2020)

5. M. van der Steen, AAAJ, 22 (5), 736 (2009)

6. Y. Wu, X. Wang, Cyber Security Intelligence and Analytics, 26 (2020)

7. P. Clarke, Managerial Accounting: Costing, Decision-Making and Control (2016)

8. G. Klychova, A. Zakirova, S. Alibekov, A. Klychova, V. Morunov, U. Raheem Adv. Intell. Syst. Comput., 1258, 669 (2021)

9. R. Heinzelmann, Controlling - Aktuelle Entwicklungen und Herausforderungen (2019)

10. A. Pereira, P. Petrali, A. Pagani, J. Barbosa, P. Leitão, INDIN, 1129-11342017 (2017)

11. A. Realyvásquez-Vargas, K. Arredondo-Soto, T. Carrillo-Gutiérrez, G. Ravelo, Appl. Sci. 8(11), 1 (2018) 